\title{
Breast Self-Examination and Breast Cancer Awareness among Women in a Low Socioeconomic Area of Chennai, India
}

\author{
Abinaya Valli Venkatesh Kumar'1, Vishnu Vardhan Yenuganti \\ 1,2 Department of Community Medicine, Chettinad Health and Research Institute, Kelambakkam, Tamil Nadu, India.
}

\section{ABSTRACT}

\section{BACKGROUND}

Breast cancer is the second major cause of cancer mortality in women and is one of the important public health concerns of modern era. This suggests that the methods for early detection of breast cancer needs to be communicated to the general population. Breast self - examination (BSE) is one of the simplest ways of screening in breast cancer and this study intends to find the knowledge regarding breast cancer and BSE.

\section{METHODS}

This is a cross-sectional study conducted in women of reproductive age group belonging to an urban slum of Chennai. A sample of 170 women above 20 years of age were interviewed randomly using a pretested questionnaire in the local language. Ethical clearance was obtained from the IHEC of the Institution and proper informed consent was taken from the women included in the study.

\section{RESULTS}

In the study, we have identified that majority (84.7 \%) of the women had awareness about breast cancer, but only 49 out of 170 were not aware that prevention is possible. Only $38.8 \%$ of the subjects had heard of breast self-examination and among them, only $5.3 \%$ had performed the BSE for cancer screening. Less than $2 \%$ of the study population were fully aware about the procedure. Awareness regarding the disease is significantly associated with factors like age, education, and socioeconomic status. $(\mathrm{P}<0.001)$

\section{CONCLUSIONS}

Based on the study findings, poor knowledge about BSE and the breast cancer prevention methods was observed in this study suggesting the need to educate the high-risk age groups of women especially in low socioeconomic group.

\section{KEY WORDS}

Breast Cancer, Breast Self - Examination, Mammography, Reproductive Age Group, Cancer Awareness, Cancer Prevention, Risk Factors
Corresponding Author: Dr. Vishnu Vardhan Yenuganti, Department of Community Medicine, Chettinad Health and Research Institute, Kelambakkam, Tamil Nadu, India.

E-mail: drvishnu44@gmail.com

DOI: $10.14260 / j e m d s / 2021 / 331$

How to Cite This Article:

Kumar AVV, Yenuganti VV. Breast selfexamination and breast cancer awareness among women in a low socioeconomic area of Chennai, India. J Evolution Med Dent Sci 2021;10(21):1588-1592, 10.14260/jemds/2021/331 DOI:

Submission 04-01-2021,

Peer Review 24-03-2021,

Acceptance 31-03-2021,

Published 24-05-2021.

Copyright (C) 2021 Abinaya Valli Venkatesh Kumar et al. This is an open access article distributed under Creative Commons Attribution License [Attribution 4.0 International (CC BY 4.0)] 


\section{BACKGROUND}

Globally, breast cancer is the main cause of cancer related morbidity and mortality among women. Being the second major cause of cancer mortality among women, it is considered a leading public health concern. In India, it is the second most prevalent cancer in women and around 80,000 cases are being diagnosed every year. A recent study established that approximately 1 in 26 women are expected to be diagnosed with breast cancer in their lifetime. ${ }^{1}$

The high incidence, high case fatality rate and the high cost of treatment in breast cancer shows us that it should be focus of attention for both the health authorities and the policy makers. The knowledge and the care seeking attitude regarding breast cancer management is very low, as the majority of the affected patients usually present late in the hospital when prevention wouldn't matter anymore. So, prevention continues to be the key concept in fighting breast cancer. Even though some prevention methods already exist many of such methods remain inaccessible to the women in developing countries. ${ }^{2}$ Early Diagnosis of breast cancer has been significantly associated with decrease in mortality, morbidity and also in the subsequent management, thereby reducing the cost of treatment. ${ }^{3}$

Many types of preventive techniques exist that are recommended to reduce breast cancer mortality and morbidity. The most common techniques that currently exist are breast self - examination (BSE), clinical breast examination (CBE), and mammography.

CBE and mammography can only be done in a hospital visit, and they also need specialized equipment and professional expertise. But BSE is a simplified, cost-free tool that can be carried out by the general population themselves. ${ }^{4}$ BSE is nothing but understanding the normal look and feel of one's breast by visualising and palpating, and to identify any changes in shape, outline, colour and texture of the skin and nipple, should they occur in future. ${ }^{3}$

Several studies have already shown that almost all the barriers in the diagnosis and treatment will be easily solved by increasing the women's awareness of breast cancer. It was found in literature that most of the times, the person themselves will identify the changes in their breast and suspect breast cancer. 5

American cancer society suggests that all the women aged between 20 - 65 years should have the necessary knowledge to understand and practice BSE regularly. ${ }^{6}$ Literature regarding breast cancer has shown that women above 20 years of age should be the target population for health education. 5,7

The present study was done to assess the levels of knowledge and practice of BSE among the market women, and those that were identified with low awareness levels will be taught BSE and other breast cancer concepts, and thus help in achieving greater awareness in the community.

\section{METHODS}

A cross-sectional study was conducted in women of more than 20 years of age, who were residing in low socioeconomic market area of an urban slum in Chennai from April 2019 to
September 2019. Participation in the study was by voluntary basis and informed consent was taken. Data collection was done by direct face to face interview using a pretested, closeended questionnaire. The questionnaire was adapted primarily from the open accessed cancer journal by Madubogwu et al. ${ }^{6}$ and it was further improvised based on research from other similar studies. ${ }^{4,5}$

Participants were identified by convenient and consecutive sampling of eligible women met either at their homes or on the streets in the sampling area. Women already affected with breast pathology and those who answered incompletely were excluded from the study.

The questionnaire consisted of Demographic variables, knowledge, attitude and practices regarding BSE and knowledge about breast cancer. Categorical responses (Yes / No / Don't know) were taken for knowledge items. Positive answers were given score 1 , and negative answers as zero.

Knowledge scores were considered as fully aware if the subject responded correctly to all questions, and as partially aware if subject responded correctly for more than half questions. 5 point Likert scale was used to assess attitude and practices. The cut off scores for attitude and practices regarding BSE were based on Likert scale responses.

This study was approved by the Institute Undergraduate Screening Committee (for ICMR - STS). The study was initiated after obtaining the approval from the Institutional Human Ethics Committee.

Design effect was not considered while calculating the sample size due to the convenient sampling method. The total sample size for the study came around to be 170 , calculated by using the following formula.

Sample size $=4 \mathrm{p} \mathrm{q} / \mathrm{d}^{\wedge} 2$, where $\mathrm{d}=15 \%$ of prevalence assuming maximum variance in the prevalence of awareness about BSE, $\mathrm{P}$ is $50 \% \mathrm{~N}=4 * 50 * 50=170 / 7.5 * 7.5$.

\section{Statistical Analysis}

Observations from the study were presented as frequency tables using Microsoft Excel. Individual association between knowledge and the variables were analysed using chi-square test, and $\mathrm{p}$ value less than 0.05 was considered significant. Logistic regression was used to establish association between selected variables and overall awareness by adjusting for confounders. Statistics was done using IBM SPSS version 24.

\section{RESULTS}

In the present study, most of the respondents belonged to the age group $41-45$ yrs. (16\%), and $36-40$ (14.7\%) whereas younger age group from 20 - 30 represented only $23 \%$ of the study population. 144 out of 170 subjects $(84.7 \%)$ had knowledge and awareness about Breast cancer, and $15.3 \%$ had not even heard about it. Among the 144 aware women, $29.4 \%$ women thought that fatty foods were the important risk factors in developing breast cancer, while $41.2 \%$ thought that sedentary lifestyle and family history were the major risk factors. Only $3.6 \%$ of the respondents thought that cigarettes and alcohol were risk factors for Breast cancer. 


\begin{tabular}{|cccc|}
\hline & Questions & N $=\mathbf{1 7 0}$ & Percent \\
Do you know about & Yes & 144 & 84.7 \\
Breast Cancer? & No & 26 & 15.3 \\
& Not Aware & 26 & 15.3 \\
& Alcohol & 4 & 2.4 \\
Risk factors in Breast & Cigarettes & 2 & 1.2 \\
Cancer? & Sedentary lifestyle & 35 & 20.6 \\
& Fatty foods & 50 & 29.4 \\
& Family history & 35 & 20.6 \\
& Others & 18 & 10.6 \\
& Not aware & 49 & 28.8 \\
Which of the following & Healthy diet & 45 & 26.5 \\
prevents Breast & Exercise & 31 & 18.2 \\
cancer? & Vaccination & 5 & 2.9 \\
& BSE & 26 & 15.3 \\
& Manage Stress levels & 8 & 4.7 \\
What are the & Smoking \& Alcohol & 6 & 3.5 \\
treatment options in & Not aware & 37 & 21.8 \\
Breast Cancer? & Medicines & 39 & 22.9 \\
& Surgery & 57 & 33.5 \\
& Spiritually & 14 & 8.2 \\
\hline & Radiologically & 23 & 13.5 \\
\hline Table 1. Knowledge with Regard to Breast Cancer & \\
\hline
\end{tabular}

In the knowledge about Prevention of breast cancer, 121 out of 170 respondents were aware that the breast cancer could be prevented. $26.5 \%$ thought that healthy diet could prevent the disease, and $18.2 \%$ thought that exercise was the key to the control of breast cancer.

133 subjects were aware that breast cancer could be treated, and majority (33.5\%) of them thought that surgery was the treatment option available, whereas $22.9 \%$ thought that medicines were the only treatment options available. Around $8.2 \%$ believed that breast cancer could be treated spiritually (Table 1 ).

In the current study, we have asked about Breast selfexamination awareness and out of the 170 subjects, only 66 women have heard about the term Breast self-examination, and also majority of them are not fully aware of what it means.

Among the 27 respondents who said that they knew to perform BSE, 10.6 \% said BSE was conducted using same side hand, whereas 9 women said opposite side hand was used to conduct BSE. Among these 27 respondents only $1.8 \%$ performed BSE monthly, 3 respondents performed BSE every six months and one respondent performed BSE once a year. 163 out of 170 women never conducted BSE in their life. 143 out of $170(84.1 \%)$ had no knowledge regarding the practice. (Table 2)

\begin{tabular}{|c|c|c|c|}
\hline \multicolumn{2}{|l|}{ Questions } & $N=170$ & Percent \\
\hline \multirow{2}{*}{ Have you heard about BSE? } & Yes & 66 & 38.8 \\
\hline & No & 104 & 61.2 \\
\hline \multirow{3}{*}{ Do you know how to perform BSE? } & Yes & 27 & 15.9 \\
\hline & No & 143 & 84.1 \\
\hline & Not aware & 143 & 84.1 \\
\hline \multirow[t]{3}{*}{ Which hand do you use for BSE? } & Same side hand & 18 & 10.6 \\
\hline & Opposite side hand & 9 & 5.3 \\
\hline & Monthly & 3 & 1.8 \\
\hline \multirow{4}{*}{$\begin{array}{l}\text { How many times do you conduct } \\
\text { BSE? }\end{array}$} & Every 6 months & 3 & 1.8 \\
\hline & Yearly & 1 & .6 \\
\hline & Never & 163 & 95.8 \\
\hline & Important & 66 & 38.8 \\
\hline \multirow[t]{3}{*}{ What do you think about BSE? } & Not important & 0 & 0 \\
\hline & No idea & 104 & 61.2 \\
\hline & Total & 170 & 100.0 \\
\hline \multicolumn{4}{|c|}{ Table 2. Awareness Regarding BSE } \\
\hline
\end{tabular}

Overall awareness includes both fully aware and partially aware subjects. Only 3 out of 170 (1.76\%) were fully aware about BSE. About $37.05 \%$ (63 out of 170 ) were partially aware and majority (104 out of 170) were completely not aware about BSE (Figure 1).

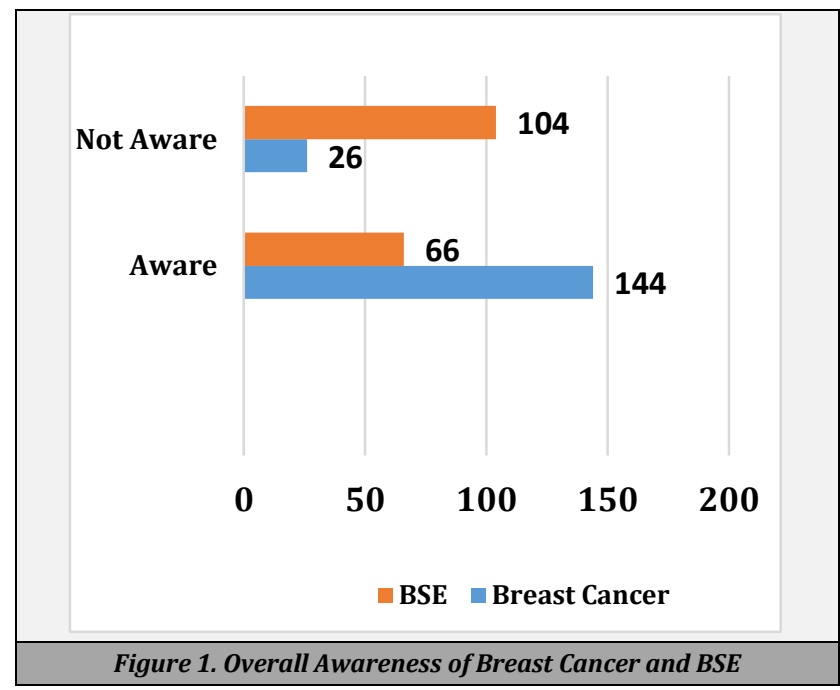

When analysed the significance of the knowledge on BSE among the socio-demographic factors of the respondents, we identified that awareness on BSE was associated with education of the subject and age of the subject. Association between age of the subject and overall awareness about BSE was statistically significant with a P value of 0.001 .

Education of the respondent was found to be important, as with increased education, knowledge on BSE had significantly increased, and the association was also statistically significant ( $P$ value is 0.000). Even though religion and Marital status had played a role in the overall awareness of BSE, the associations were not statistically significant (Table 3 ).

\begin{tabular}{|c|c|c|c|c|c|}
\hline & & \multicolumn{3}{|c|}{ BSE overall Awareness } & \multirow[b]{2}{*}{ P Value } \\
\hline & & Not aware & $\begin{array}{c}\text { Partially } \\
\text { aware }\end{array}$ & $\begin{array}{c}\text { Fully } \\
\text { aware }\end{array}$ & \\
\hline \multirow{8}{*}{ Age (Yrs.) } & $20-25$ & 8 & 9 & 0 & \multirow{8}{*}{$\mathrm{P}=0.002^{*}$} \\
\hline & $26-30$ & 7 & 14 & 1 & \\
\hline & $31-35$ & 7 & 12 & 0 & \\
\hline & $36-40$ & 8 & 15 & 2 & \\
\hline & $41-45$ & 17 & 10 & 0 & \\
\hline & $46-50$ & 21 & 3 & 0 & \\
\hline & $51-55$ & 21 & 0 & 0 & \\
\hline & $56-60$ & 15 & 0 & 0 & \\
\hline \multirow{4}{*}{ Marriage } & Unmarried & 10 & 20 & 0 & \multirow{4}{*}{$\mathrm{P}=0.05$} \\
\hline & Married & 67 & 29 & 3 & \\
\hline & Divorced & 6 & 7 & 0 & \\
\hline & Widowed & 21 & 7 & 0 & \\
\hline \multirow{5}{*}{ Education } & Illiterate & 23 & 0 & 0 & \multirow{5}{*}{$\mathrm{P}<0.001^{*}$} \\
\hline & Primary & 39 & 8 & 0 & \\
\hline & Secondary & 34 & 24 & 0 & \\
\hline & Inter & 7 & 22 & 1 & \\
\hline & Graduate & 1 & 9 & 2 & \\
\hline \multirow{3}{*}{ Religion } & Hindu & 61 & 34 & 1 & \multirow{3}{*}{$P=0.06$} \\
\hline & Muslim & 17 & 19 & 0 & \\
\hline & Christian & 26 & 10 & 2 & \\
\hline \multicolumn{6}{|c|}{ Table 3. Association of Demographic Factors with Overall Awareness } \\
\hline
\end{tabular}

\section{DISCUSSION}

With the incidence of rising breast cancer, and lack of any national breast screening programme in India, it is pertinent to learn about the knowledge and practice of BSE in the women. In this study, we have collected the data from women in low socioeconomic area, as to include all the age groups and identify their knowledge on breast self-examination. The overall knowledge of BSE in the study subjects was found to be inadequate. This finding was found to be consistent with the study by Yadav and Jaroli among Indian college going students 
in Rajasthan wherein $28 \%$ examined their breasts rarely or never. ${ }^{8}$

Similarly, we also found that only seven women in our sample of 170 had examined their breasts at all in their lifetime. In a study done in female health care professionals, $75.1 \%$ showed higher knowledge percentage compared to our study where only $38.8 \%$ heard about BSE at all. ${ }^{9}$ This difference shows us that education is the most important factor in assessing knowledge. The women in low socioeconomic area had never received any sort of education or training on breast cancer screening methods, and without any such health educational campaign, the knowledge diminishes further. In the current study, overall awareness on breast cancer was significantly lower among the women with lesser education which is consistent with the study done through the internet. 10

There is a negative correlation between the knowledge and practice of the BSE among the women in our study, where only $4.2 \%$ were practicing the BSE at least once annually. The knowledge on breast cancer prevention among the women in our study is adequate, although 49 out of 170 subjects were never aware that prevention was possible. This is similar to a result established in a study of knowledge toward breast cancer, which showed that the subjects with low scores regarding its prevention were less likely to be interested in knowing how to prevent breast cancer. ${ }^{11}$

In knowledge about risk factors, only 26 were not aware of any risk factors, whereas $49.4 \%$ thought that fatty foods and sedentary lifestyle were major causative factors of breast cancer, which was inconsistent with the study done in urban women, that showed $35 \%$ of them were aware of the risk factors and majority of them believed age as an important risk factor. 12

In a review article from India, it was reported that regardless of their socioeconomic and educational background, there was no improvement in the knowledge of risk factors for breast cancer over an 8-year period among 7066 women aged $15-70$ years. The study subjects in the article had shown varying levels of awareness of risk factors such as family history $(13-58 \%)$, reproductive history (1 $88 \%)$ and obesity $(11-51 \%) .{ }^{13}$

The role of awareness in learning breast self - examination as a tool in detecting breast cancer at an early stage is controversial and the American Cancer Society (ACS) was against in recommending it, because they thought it would increase anxiety among them and might not help in increasing the survival rate. ${ }^{12}$ Conversely, BSE was highly advocated for women in the developing countries where mammographybased screening programs were known to be poorly performed. ${ }^{14}$

\section{CONCLUSIONS}

Knowledge of breast cancer is adequate among the women in low socioeconomic area, whereas knowledge regarding its prevention was limited. The importance of breast selfexamination was almost unknown to the majority of the women involved in the study. Though enough women had heard about it, they were still unaware about how to conduct it. These results of poor knowledge indicated the need for efforts in increasing health education among the women, especially those in low socioeconomic group. Due to lack of specific targeted health education regarding BSE, pamphlets in regional language containing the importance and steps of BSE, along with illustrations depicting the changes in breast were distributed to the study subjects.

Data sharing statement provided by the authors is available with the full text of this article at jemds.com.

Financial or other competing interests: None.

Disclosure forms provided by the authors are available with the full text of this article at jemds.com.

\section{REFERENCES}

[1] Raina V, Bhutani M, Bedi R, et al. Clinical features and prognostic factors of early breast cancer at a major cancer center in North India. Indian J Cancer 2005;42(1):40-5.

[2] Madhukumar S, Thambiran UR, Basavaraju B, et al. A study on awareness about breast carcinoma and practice of breast self-examination among basic sciences college students, Bengaluru. J Family Med Prim Care 2017;6(3):487-90.

[3] Obaji NC, Elom HA, Agwu UM, et al. Awareness and practice of breast self-examination among market women in Abakaliki, South East Nigeria. Ann Med Health Sci Res 2013;3(1):7-12.

[4] Doshi D, Reddy BS, Kulkarni S, et al. Breast selfexamination: knowledge, attitude and practice among female dental students in Hyderabad city, India. Indian J Palliat Care 2012;18(1):68-73.

[5] Karayurt Ö, Özmen D, Çetinkaya AC. Awareness of breast cancer risk factors and practice of breast self examination among high school students in Turkey. BMC Public Health 2008;8(1):359.

[6] Smith RA, Cokkinides V, Eyre HJ. American Cancer Society guidelines for the early detection of cancer, 2004. CA: A Cancer Journal for Clinicians 2004;54(1):41-52.

[7] Madubogwu CI, Egwuonwu AO, Madubogwu NU, et al. Breast cancer screening practices amongst female tertiary health worker in Nnewi. J Cancer Res Ther 2017;13(2):268-75.

[8] Yadav P, Jaroli DP. Breast cancer: awareness and risk factors in college-going younger age group women in Rajasthan. Asian Pac J Cancer Prev 2010;11(2):319-22.

[9] Getu MA, Kassaw MW, Tlaye KG, et al. Assessment of breast self-examination practice and its associated factors among female undergraduate students in Addis Ababa University, Addis Ababa, Ethiopia, 2016. Breast Cancer (Dove Med Press) 2019;11:21-8.

[10] Atuhairwe C, Amongin D, Agaba E, et al. The effect of knowledge on uptake of breast cancer prevention modalities among women in Kyadondo County, Uganda. BMC Public Health 2018;18(1):279.

[11] Somdatta P, Baridalyne N. Awareness of breast cancer in women of an urban resettlement colony. Indian J Cancer 2008;45(4):149-53.

[12] Gupta A, Shridhar K, Dhillon PK. A review of breast cancer awareness among women in India: cancer literate or awareness deficit? Eur J Cancer 2015;51(14):2058-66. 
[13] Knutson D, Steiner E. Screening for breast cancer: current recommendations and future directions. Am Fam Physician 2007;75(11):1660-6.
[14] Okobia MN, Bunker CH, Okonofua FE, et al. Knowledge, attitude and practice of Nigerian women towards breast cancer: a cross-sectional study. World J Surg Oncol 2006;4(1):11. 